\title{
Wall Thickness Measurement of Pipes by Using Digital Radiography
}

\author{
M. Cobanoglu, N. Altinsoy*
}

Istanbul Technical University (ITU), Energy Institute, Ayazaga Kampusu,34469 Istanbul, Turkey

\begin{abstract}
One of the most important parameters in a pipeline to be monitored and measured is the wall thickness. Pipe wall thickness can vary after a certain period of time, as a result of accumulation of various chemical or physical effects. Pipe wall thickness can be monitored by the proper use of ultrasonic or radiographic inspection methods even while the plant is in operation. Only the radiographic method assures inspection without costly removal of insulation material during operation of the plant. The purpose of this study is to define the wall thickness of pipes by using digital radiography technique. The outer diameter of the studied pipes is ranging from $51 \mathrm{~mm}$ to $60.3 \mathrm{~mm}$ and wall thickness is ranging from $2.9 \mathrm{~mm}$ to $3.6 \mathrm{~mm}$. Experiments were repeated by changing the "focal detector distance" and "pulse" parameters.
\end{abstract}

DOI: 10.12693/APhysPolA.127.1261

PACS: 25.20.Dc

\section{Introduction}

Steel pipes are widely used for liquid and gas transportation in the petroleum and chemical industries. corrosion, erosion, wear and deposit formation cause changes of pipe wall thickness over time. Even the slightest change can affect the pipes ability to withstand pressures and meet relevant operation requirements. Thus the accurate measurement of the pipe walls is a vitally important test. Digital radiography systems can be monitored and measured the wall thickness of pipes rapidly and instantly $[1,2]$. In this study, wall thickness of pipes was measured by digital radiography using tangential technique. For this purpose, "foX-Rayzor" digital radiography system which has a flat panel detector was used. Radiographic image of pipe was obtained by flat panel detector and transferred to computer as a digital image. Thus measurements have been able to identify precisely and quickly. Exposure process was repeated according to operating parameters that are "focal detector distance" and "pulse" parameters.

\section{Experimantal study}

In this study, 9 different steel pipe samples were studied at ITU Energy Institute, radiography laboratory. These samples have 3 different diameters and each one has 3 different wall thicknesses as shown in Table I. Pipe samples are each $20 \mathrm{~cm}$ in length and welded pipe production standards EN 10217-2, P 235 GH (ST 37.8) and higher quality materials. Such pipes are used especially in industry, boiler, steam and heat exchanger tubes. The outer diameters of the pipes, wall thicknesses and maximum penetrable wall thickness of pipes $\left(L_{\max }\right)$ are shown in Table I.

${ }^{*}$ corresponding author; e-mail: altinsoy@itu.edu.tr
Pipe samples outside diameters, TABLE I wall thickness and $L_{\max }$ values.

\begin{tabular}{c|c|c|c}
\hline \hline Sample & $\begin{array}{c}\text { Outer } \\
\text { diameter }[\mathrm{mm}]\end{array}$ & $\begin{array}{c}\text { Wall } \\
\text { thickness }[\mathrm{mm}]\end{array}$ & $\begin{array}{c}L_{\max } \\
{[\mathrm{mm}]}\end{array}$ \\
\hline 1 & & 2.9 & 23.62 \\
2 & 51 & 3.2 & 24.74 \\
3 & & 3.6 & 26.13 \\
\hline 4 & & 2.9 & 25.05 \\
5 & 57 & 3.2 & 26.24 \\
6 & & 3.6 & 27.73 \\
\hline 7 & \multirow{3}{*}{60.3} & 2.9 & 25.80 \\
8 & & 3.2 & 27.03 \\
9 & & 3.6 & 28.57
\end{tabular}

The system used in this study was a foX-Rayzor portable X-ray inspection system which contains the flat amorphous Silicon (a-Si) 14 bit (16,384 gray levels) panel, with $270 \mathrm{kV}$ pulsed X-ray source. The experimental setup was prepared on suitable geometry in the exposure room of radiography laboratory as shown in Fig. 1. The whole concept of tangential radiography is to penetrate the sidewall of the pipe so that the thickness is projected on to the flat panel detector. As there will be some magnification of the image it is essential that the set-up is controlled. A suitable focal detector distance must be chosen to reduce the geometric unsharpness of the image [3-5]. The wall thicknesses are directly read from the obtained digital images and the thickness detection is simultaneously done with the help of pixel intensity profile as shown in Fig. 2. This process was repeated for 9 pipes on 80 pulse and 90 pulse values at 600 and $700 \mathrm{~mm}$ focal detector distances.

\section{Results and discussion}

The digital images and pixel intensity profiles of Sample 1 for four different operating parameters are given in Fig. 2. Pixel intensity is decreasing with increasing focal detector distance when the pulse values are the same 


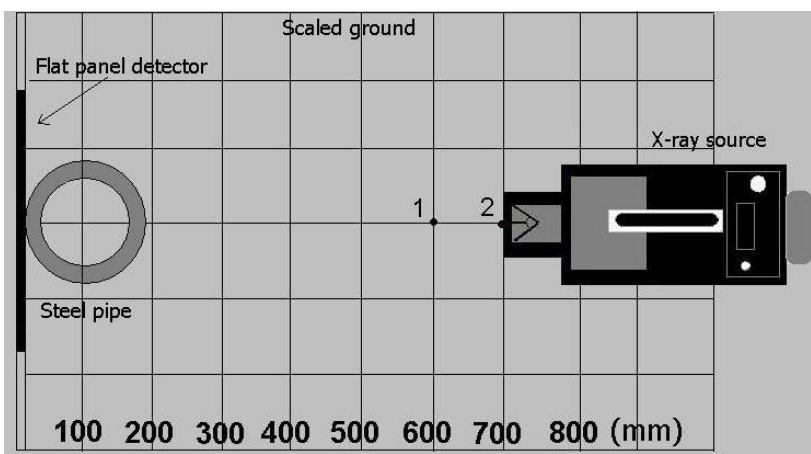

Fig. 1. Schematic representation of the experimental setup.

(Fig. 2a, b). At the same focal detector distance, an increase in pixel intensity was observed by increasing pulse value (Fig. 2a, c). At the same time, the sharpness of the turning point is also increasing with the increasing pulse value in pixel intensity profile (Fig. 2c, d)

Three different thickness values were read on the same region of the digital image and the arithmetic averages were calculated. The corrected wall thickness $(w)$ was calculated by Eq. 1 using average wall thickness $\left(w^{\prime}\right)$ [1].

$$
w=\frac{(1-R)}{F D D} w^{\prime}
$$

In Eq. 1, $R$ is the radius of pipe, $F D D$ is focal detector distance. These values are given together in Table II for different operating parameters.

In the experiments, differences between the real wall thicknesses and corrected wall thicknesses were evaluated as error. The absolute error results depending on operating parameters are given together in Fig. 3. According to Fig. 3, when the wall thickness increases, the absolute errors are generally reduced (Fig. 3a, Fig. 2b). Absolute error is increasing with the decreasing focal detector distance while keeping pulse values constant (Fig. 3a, Fig. 2b, Fig. 2c). This situation can be explained with geometric unsharpness which is decreased with the increasing focal detector distance.

\section{Conclusion}

In the study, wall thickness of different steel pipes was measured by digital radiography using tangential technique. The outer diameter of the studied pipes is ranging from $51 \mathrm{~mm}$ to $60.3 \mathrm{~mm}$ and wall thickness is ranging from $2.9 \mathrm{~mm}$ to $3.6 \mathrm{~mm}$. Experiments were repeated for 9 pipes on 80 pulse and 90 pulse values at 600 and $700 \mathrm{~mm}$ focal detector distances. The wall thicknesses were obtained from pixel intensity profiles and digital images of the pipes.

It was found that the pixel intensity decreases with the increasing focal detector distance when the pulse values are the same. An increase in pixel intensity was observed by increasing pulse value at the same focal detector distance. At the same time, the sharpness of the turning
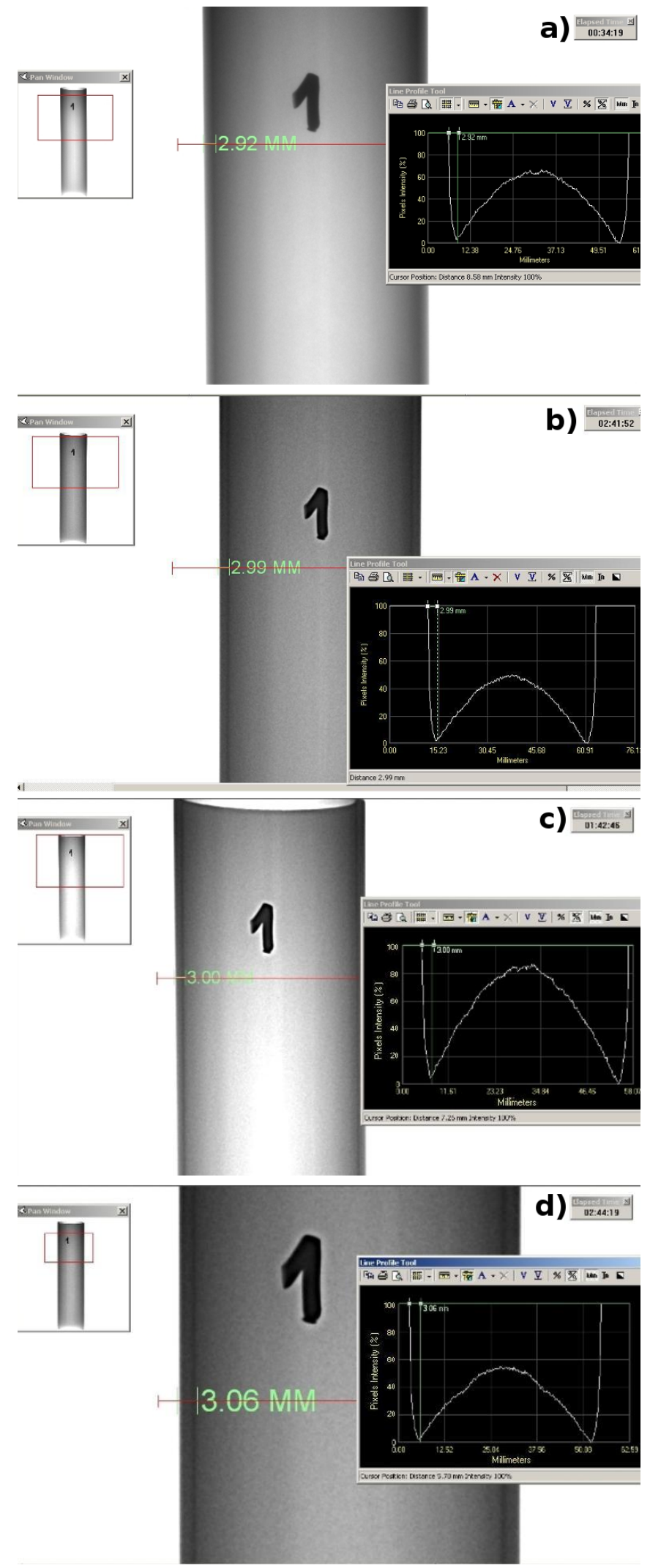

Fig. 2. Digital images and the pixel intensity profiles of Sample 1 for (a) 80 pulse $600 \mathrm{~mm}$, (b) 80 pulse $700 \mathrm{~mm}$, (c) 90 pulse $600 \mathrm{~mm}$, (d) 90 pulse $700 \mathrm{~mm}$. 
Average and corrected wall thicknesses for different operating

TABLE II parameters.

\begin{tabular}{|c|c|c|c|c|}
\hline Sample & Pulse & $\begin{array}{c}\text { Focal } \\
\text { Detector } \\
\text { Distance } \\
{[\mathrm{mm}]}\end{array}$ & $\begin{array}{c}\text { Average } \\
\text { wall } \\
\text { thickness, } \\
w^{\prime}[\mathrm{mm}]\end{array}$ & $\begin{array}{c}\text { Corrected } \\
\text { wall } \\
\text { thickness, } \\
w[\mathrm{~mm}]\end{array}$ \\
\hline 1 & \multirow{9}{*}{80} & \multirow{9}{*}{600} & $2.93 \pm 0.04$ & 2.81 \\
\hline 2 & & & $3.25 \pm 0.09$ & 3.12 \\
\hline 3 & & & $3.80 \pm 0.15$ & 3.64 \\
\hline 4 & & & $2.94 \pm 0.09$ & 2.80 \\
\hline 5 & & & $3.41 \pm 0.04$ & 3.25 \\
\hline 6 & & & $3.75 \pm 0.13$ & 3.57 \\
\hline 7 & & & $3.07 \pm 0.01$ & 2.94 \\
\hline 8 & & & $3.31 \pm 0.05$ & 3.16 \\
\hline 9 & & & $3.78 \pm 0.05$ & 3.59 \\
\hline 1 & \multirow{9}{*}{80} & \multirow{9}{*}{700} & $2.92 \pm 0.11$ & 2.81 \\
\hline 2 & & & $3.35 \pm 0.12$ & 3.23 \\
\hline 3 & & & $3.76 \pm 0.08$ & 3.63 \\
\hline 4 & & & $2.95 \pm 0.07$ & 2.83 \\
\hline 5 & & & $3.29 \pm 0.08$ & 3.16 \\
\hline 6 & & & $3.76 \pm 0.08$ & 3.61 \\
\hline 7 & & & $3.01 \pm 0.08$ & 2.88 \\
\hline 8 & & & $3.35 \pm 0.07$ & 3.21 \\
\hline 9 & & & $3.76 \pm 0.08$ & 3.60 \\
\hline 1 & \multirow{9}{*}{90} & \multirow{9}{*}{600} & $2.94 \pm 0.06$ & 2.82 \\
\hline 2 & & & $3.26 \pm 0.07$ & 3.12 \\
\hline 3 & & & $3.72 \pm 0.08$ & 3.56 \\
\hline 4 & & & $3.02 \pm 0.05$ & 2.87 \\
\hline 5 & & & $3.39 \pm 0.11$ & 3.23 \\
\hline 6 & & & $3.76 \pm 0.03$ & 3.58 \\
\hline 7 & & & $3.00 \pm 0.06$ & 2.85 \\
\hline 8 & & & $3.31 \pm 0.07$ & 3.14 \\
\hline 9 & & & $3.74 \pm 0.07$ & 3.55 \\
\hline 1 & \multirow{9}{*}{90} & \multirow{9}{*}{700} & $3.06 \pm 0.08$ & 2.95 \\
\hline 2 & & & $3.28 \pm 0.02$ & 3.16 \\
\hline 3 & & & $3.70 \pm 0.07$ & 3.57 \\
\hline 4 & & & $3.04 \pm 0.05$ & 2.92 \\
\hline 5 & & & $3.36 \pm 0.08$ & 3.22 \\
\hline 6 & & & $3.76 \pm 0.05$ & 3.61 \\
\hline 7 & & & $2.99 \pm 0.09$ & 2.86 \\
\hline 8 & & & $3.30 \pm 0.06$ & 3.16 \\
\hline 9 & & & $3.74 \pm 0.09$ & 3.58 \\
\hline
\end{tabular}

point also increases with the increasing pulse value in pixel intensity profile.

The absolute error results show that when the wall thickness increases, the absolute errors are generally reduced. Absolute error increases with the decreasing focal detector distance while keeping pulse values constant. It is also observed that the pulse changes does not affect the absolute error, but only affects the quality of digital image. In our study, the maximum absolute percentage error was found 3.45 for the pipe samples which are in the range of $23 \mathrm{~mm}<L_{\max }<29 \mathrm{~mm}$. These values are within acceptable accuracy limits.

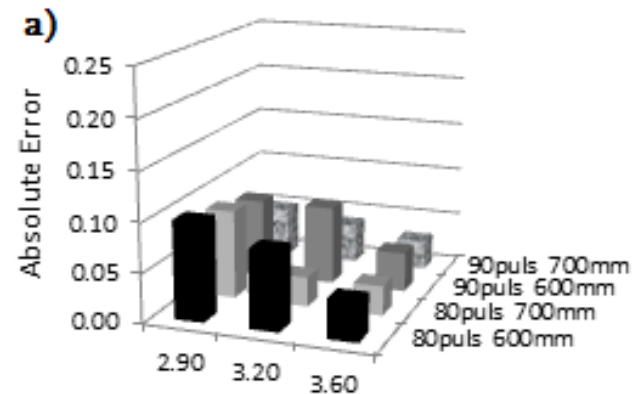

Real Wall Thickness

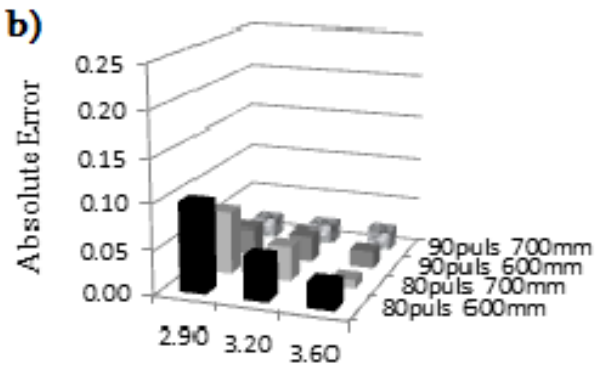

Real Wall Thickness

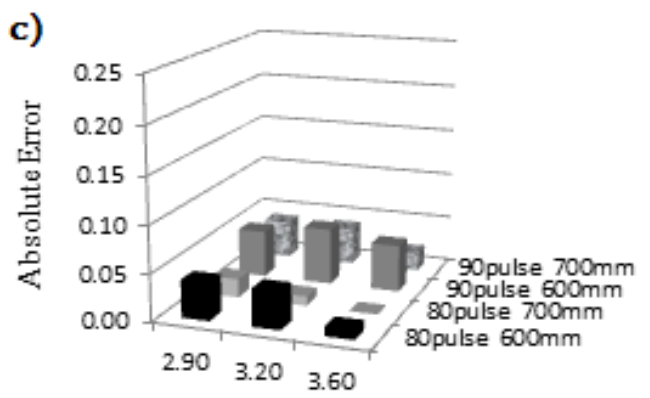

Real Wall Thickness

Fig. 3. Absolute error values for outer diameter of (a) $51 \mathrm{~mm}$. (b) $57 \mathrm{~mm}$ and (c) $60.3 \mathrm{~mm}$ pipe samples.

\section{References}

[1] W. Harara in: IAEA-TECDOC-1445, 85, Vienna, Austria 2005.

[2] U. Zscherpel, S. Ekinci in: Radiographic Evaluation of Corrosion and Deposits in Pipelines: Result of an IAEA Coordinated Research Program, IAEA-INIS, 38/5 2006.

[3] Ş. Ekinci, N. Baş, M. Aksu, A. Yıldırım, M. Bingöldağ, T. Kurtcebe, M. Doğruöz, S. Sarıçam, N. Yılmaz, Insight 40/9, 628 (1998).

[4] Edalati, N. Rastkhah, A. Kermani, M. Seiedi, A. Movafeghi, International Journal of Pressure Vessels and Piping 83, 736 (2007).

[5] U. Ewert, Codes and Standards in Digital Industrial Radiology, BAM, Chennai, India 2007. 